\title{
Effectiveness of 3 COVID-19 Vaccines in Preventing SARS-CoV-2 Infections, January-May 2021, Aragon, Spain
}

\author{
Alicia del Cura-Bilbao, Héctor López-Mendoza, Armando Chaure-Pardos, \\ Alberto Vergara-Ugarriza, Joaquín Guimbao-Bescós
}

Reducing severe acute respiratory syndrome coronavirus 2 (SARS-CoV-2) transmission is a worldwide challenge; widespread vaccination could be one strategy for control. We conducted a prospective, population-based cohort study of 964,258 residents of Aragon, Spain, during December 2020-May 2021. We used the Cox proportionalhazards model with vaccination status as the exposure condition to estimate the effectiveness of 3 coronavirus disease vaccines in preventing SARS-CoV-2 infection. PfizerBioNTech had $20.8 \%$ (95\% Cl $11.6 \%-29.0 \%$ ) vaccine effectiveness (VE) against infection after 1 dose and $70.0 \%$ (95\% Cl 65.3\%-74.1\%) after 2 doses, Moderna had $52.8 \%$ (95\% Cl 30.7\%-67.8\%) VE after 1 dose and $70.3 \%(95 \%$ Cl $52.2 \%-81.5 \%$ ) after 2 doses, and Oxford-AstraZeneca had $40.3 \%(95 \% \mathrm{Cl} 31.8 \%-47.7 \%)$ VE after 1 dose. All estimates were lower than those from previous studies. Results imply that, although high vaccination coverage remains critical to protect people from disease, it will be difficult to effectively minimize transmission opportunities.

ince the beginning of the coronavirus disease (COSVID-19) pandemic, one of the main challenges countries have experienced is finding effective ways to reduce illness and death from the disease. Nonpharmaceutical measures have been used extensively, and vaccines were added to the resources of the European Union beginning in December 2020. Re-

Author affiliations: Miguel Servet University Hospital, Zaragoza, Spain (A. del Cura-Bilbao); Aragon Department of Health, Zaragoza (A. del Cura-Bilbao, H. López-Mendoza, A. ChaurePardos, A. Vergara-Ugarriza, J. Guimbao-Bescós); University of Zaragoza CASSETEM Research Group, Zaragoza (H. LópezMendoza); Lozano Blesa University Hospital, Zaragoza (H. López-Mendoza, A. Chaure-Pardos); GRISSA Research Group, Zaragoza (A. Chaure-Pardos); Aragon Health Research Institute Foundation (IIS Aragon), Zaragoza (A. Chaure-Pardos)

DOI: https://doi.org/10.3201/eid2803.212027 sults from phase 3 and phase 4 studies have found the vaccines to be highly effective (1-12). Studies assessing the effectiveness of vaccines in real-world settings among elderly populations $(13,14)$ have also shown a high effectiveness from a single dose.

Spain has had one of the world's highest rates of illness and death from COVID-19 (15). The Aragon region, in the northeast of the country, has one of Spain's largest elderly populations; $22 \%$ of people among a total population of 1.3 million people are $\geq 65$ years of age (16). Through May 31, 2021, the region had reported 125,465 COVID-19 cases, 3,522 deaths (17), and a fatality rate of $2.8 \%$. Vaccination programs have proven to be the most effective measure to control the pandemic (18) and have been used in conjunction with hygiene and social distancing measures.

The European Union vaccination program started on December 27, 2020. Pfizer-BioNTech (BNT162b2; https://www.pfizer.com), Moderna (mRNA-1273; https://www.modernatx.com), Oxford-AstraZeneca (hAdOx1-S-AZD1222; https://www.astrazeneca.com), and Janssen (https://www.janssen.com) COVID-19 vaccines are currently authorized by the European Medicines Agency (EMA; https://www.ema.europa. eu) for administration in the European Union (19). The Pfizer-BioNTech, Moderna, and Oxford-AstraZeneca vaccines have been widely used in Spain and Aragon in accord with the vaccination strategy $(20,21)$. The Janssen vaccine was added to the vaccination plan later. As of May 31, 2021, 44\% of the population of Aragon $\geq 18$ years of age had been vaccinated with $\geq 1$ dose of vaccine, and $24.5 \%$ had been fully vaccinated (22).

The context of coexisting vaccinated and unvaccinated persons and periods of high infection rates among the general population lends urgency to performing vaccine effectiveness (VE) studies. We 
carried out a cohort study to estimate the effectiveness of vaccination in preventing severe acute respiratory syndrome coronavirus 2 (SARS-CoV-2) infection, in which we compared the Pfizer-BioNTech, Moderna, and Oxford-AstraZeneca COVID-19 vaccines.

\section{Institutional Review Board Statement}

The authors declare that they have complied with the provisions of Spanish Organic Law 3/2018 of December 5 on Personal Data Protection and Digital Rights Guarantee and with the provisions of Regulation (EU) 2016/679 of the European Parliament and of the Council of 27 April 2016 on the protection of natural persons with regard to the processing of personal data and on the free movement of such data, and repealing Directive 95/46/EC (General Data Protection Regulation). Approval for this research was obtained from the Aragon Research Ethics Committee (no. 2021/141).

\section{Methods}

We conducted a prospective, population-based cohort study of residents in the region of Aragon, Spain. Participants were all of the users of the Aragon Health Service, $\geq 16$ years old of age, who had no evidence of previous SARS-CoV-2 infection, confirmed by reverse transcription PCR (RT-PCR), antigen test, or immunoglobulin G test for SARS-CoV-2 infection at any time before December 27, 2020. We included all residents registered in the Aragon Healthcare System Users Registry (AHSUR) who met the eligibility criteria as of December 31, 2020. AHSUR consists of periodically updated basic demographic data from users of the Aragon Healthcare Service, the public healthcare provider in Aragon. AHSUR contains data from $89 \%$ of Aragon inhabitants. We based the study on data collected during December 28, 2020-May 31, 2021.

\section{Vaccination Program}

The goal of COVID-19 vaccination strategy in Spain and Aragon $(20,21)$ was to protect vulnerable and exposed populations and to achieve full vaccination in as much of the population as possible. Some priority groups were targeted for earlier vaccination during December 2020-February 2021: residents of care (nursing) or residential homes for elderly or disabled people, frontline healthcare workers, caregivers and residential home workers, second-line healthcare workers, and disabled persons not residing in a nursing or residential home. In Aragon, from February 2021 the rollout was expanded to all adults $\geq 80$ years of age and essential workers - civil protection staff, firefighters, security forces, and educational center staff. In April 2021, the rollout was extended to all adults 60-79 years of age; persons with high-risk conditions and younger age groups have been progressively incorporated into the rollout schedule (23).

Specific vaccines were incorporated into the vaccination plan at different times. In Aragon, the Pfizer-BioNTech vaccine was administered beginning December 27, 2020, the Moderna vaccine beginning January 13, 2021, and the Oxford-AstraZeneca vaccine beginning February 7, 2021 (21). Because of the stoppage in Oxford-AstraZeneca vaccination in people $<60$ years of age, those participants receiving that vaccine who we tracked in follow-up had received only 1 dose at the time of the analysis. Because only 8,727 doses of the single-dose Janssen vaccine had been administered since its initiation on April 21, 2021 (21), we excluded data on that vaccine from the analysis.

\section{Exposure Definition (Vaccination Status)}

The exposure condition was vaccination status. On each exposure condition, we followed participants, grouped by vaccination status, until that status changed because of SARS-CoV-2 infection, death, loss to follow-up, or end of the study period, whichever occurred first. For first dose vaccination, participants were defined as exposed from 12 days after 1 dose of the Pfizer-BioNTech vaccine, 14 days after 1 dose of the Moderna vaccine, and 21 days after 1 dose of the Oxford-AstraZeneca vaccine according to previous studies. For second dose vaccination, we defined participants as exposed beginning 7 days after 2 doses of the Pfizer-BioNTech vaccine, and 14 days after 2 doses of the Moderna vaccine (1-3). We defined unvaccinated participants as unexposed.

\section{Outcome Definition}

We considered a participant to be SARS-CoV-2 infected if confirmed by RT-PCR or rapid antigen detection test according to World Health Organization definitions (24). Following COVID-19 detection and surveillance guidelines in Spain and Aragon $(25,26)$, criteria to test for SARS-CoV-2 were having symptoms compatible with COVID-19 or close contact with a person with a laboratory-confirmed SARS-CoV-2 infection diagnosis. We extracted vaccination registry and laboratory testing data from the electronic medical record system of health-related information. The electronic medical record system was automatically updated with those data. 


\section{Patient Characteristics and Confounders}

We studied cohort population characteristics to determine if they could potentially act as confounders. These characteristics included age, sex, work or residence in nursing or residential homes, weekly cumulative incidence (WCI) of SARS-CoV-2 infection in each primary care service area, and number of SARS-CoV-2 tests administered in the previous 6 months. We defined SARS-CoV-2 infection WCI as the total number of newly confirmed SARS-CoV-2 infections per 100,000 inhabitants in each primary care service area within the previous 7 days. We extracted data on age, sex, and the primary care service areas from AHSUR. We extracted specific information on nursing and residential homes residents and workers from the Aragon nursing and residential homes information system, an information system to manage care, prevention, and control measures for residents and workers at nursing and residential homes in the context of the COVID-19 pandemic. We used formal tests to compare data between participants lost to follow-up and the studied cohort: $\chi^{2}$ tests for all the variables except follow-up time, for which we used Student t-tests, resulting in statistically significant $(p<0.01)$ differences for all the variables.

\section{Statistical Analysis}

We defined the incidence rate (IR) of SARS-CoV-2 infection as the number of confirmed SARS-CoV-2 infections divided by the sum of exposure times for each participant. We computed unadjusted estimators using a Cox proportional-hazards model in which only vaccination status was included, and unadjusted VE against SARS-CoV-2 infection as 1 - hazard ratio. We computed adjusted estimators using a Cox proportional-hazards model and included baseline data on age, sex, and being a resident or worker in a nursing or residential home as categorical covariates in the models. We included WCI from each primary care service area and the number of SARS-CoV-2 tests administered in the previous 6 months as time-variable terms. To introduce the time-variable terms, we split individual follow-up times into weekly intervals. Therefore, we assigned each interval the immediately previous week's WCI and introduced all intervals into the model as individual observations. We split age and WCI into 4 categories based on percentiles $0-10,11-50,51-90$, and 91-100. We calculated adjusted VE against SARS$\mathrm{CoV}-2$ infection as 1 - hazard ratio.

\section{Results}

We prospectively followed a cohort of 964,258 people $\geq 16$ years of age from the general population, corresponding to $72.5 \%$ of the population of Aragon; the size and exposure status of the cohort evolved across the study period (Figure 1). We stratified participants' vaccination exposure by their demographic characteristics (Table 1). As of May 31, 2021, among the participants, 242,142 had been vaccinated with $\geq 1$ dose of the Pfizer-BioNTech vaccine and 212,419 with 2 doses; 32,522 participants had been vaccinated with at least 1 dose of the Moderna vaccine and 15,660 of them with 2 doses; and 97,492 participants had been vaccinated with 1 dose of the Oxford-AstraZeneca vaccine; 592,102 participants had not yet been vaccinated. We observed differences in the number of Pfizer-BioNTech, Moderna, and Oxford-AstraZeneca vaccines doses administered over the study period, which occurred because of different EMA approval times, vaccine doses available over time, and prioritizing of groups considered for earlier vaccination, specifically persons $\geq 75$ years old and residents and workers in nursing and residential homes (Table 1). Over the study period, 11,557 (1.2\%) participants dropped out of the study; we recorded lost participants by demographic characteristics and causes of withdrawal (Tables 1, 2).

The 592,102 unvaccinated participants had 25,767 SARS-CoV-2 infections and an IR of 1.41/1,000 person-weeks. The 242,142 participants vaccinated with 1 dose of the Pfizer-BioNTech vaccine had 463 infections (IR 0.86) and the 212,419 with 2 doses had 280 infections (IR 0.23). The 32,522 participants vaccinated with 1 dose of the Moderna vaccine had 28 infections (IR 0.31) and the 15,660 with 2 doses had 18 infections (IR 0.21). The 97,492 participants vaccinated with 1 dose of the Oxford-AstraZeneca vaccine had 230 infections (IR 0.55).

\section{Unadjusted Vaccine Effectiveness against SARS-CoV-2 Infection}

The Pfizer-BioNTech vaccine had $23.5 \% \quad(95 \%$ CI $16.0 \%-30.3 \%$ ) unadjusted VE against SARS-CoV-2 infection after 1 dose and $76.1 \%$ (95\% CI 73.1\%-78.8\%) after 2 doses. The Moderna vaccine had 69.2\% (95\% CI $55.4 \%-78.8 \%$ ) unadjusted VE after 1 dose and $78.4 \%$ (95\% CI $65.6 \%-86.4 \%$ ) after 2 doses. The Oxford-AstraZeneca vaccine had $43.7 \%$ (95\% CI 35.7\%-50.7\%) unadjusted VE after 1 dose (Table 3 ).

\section{Adjusted Vaccine Effectiveness against SARS-CoV-2 Infection}

After adjusting for age, sex, work or residence in a nursing or residential home, WCI in each primary care service area, and number of SARS-CoV-2 tests administered in the previous 6 months, we found that the 


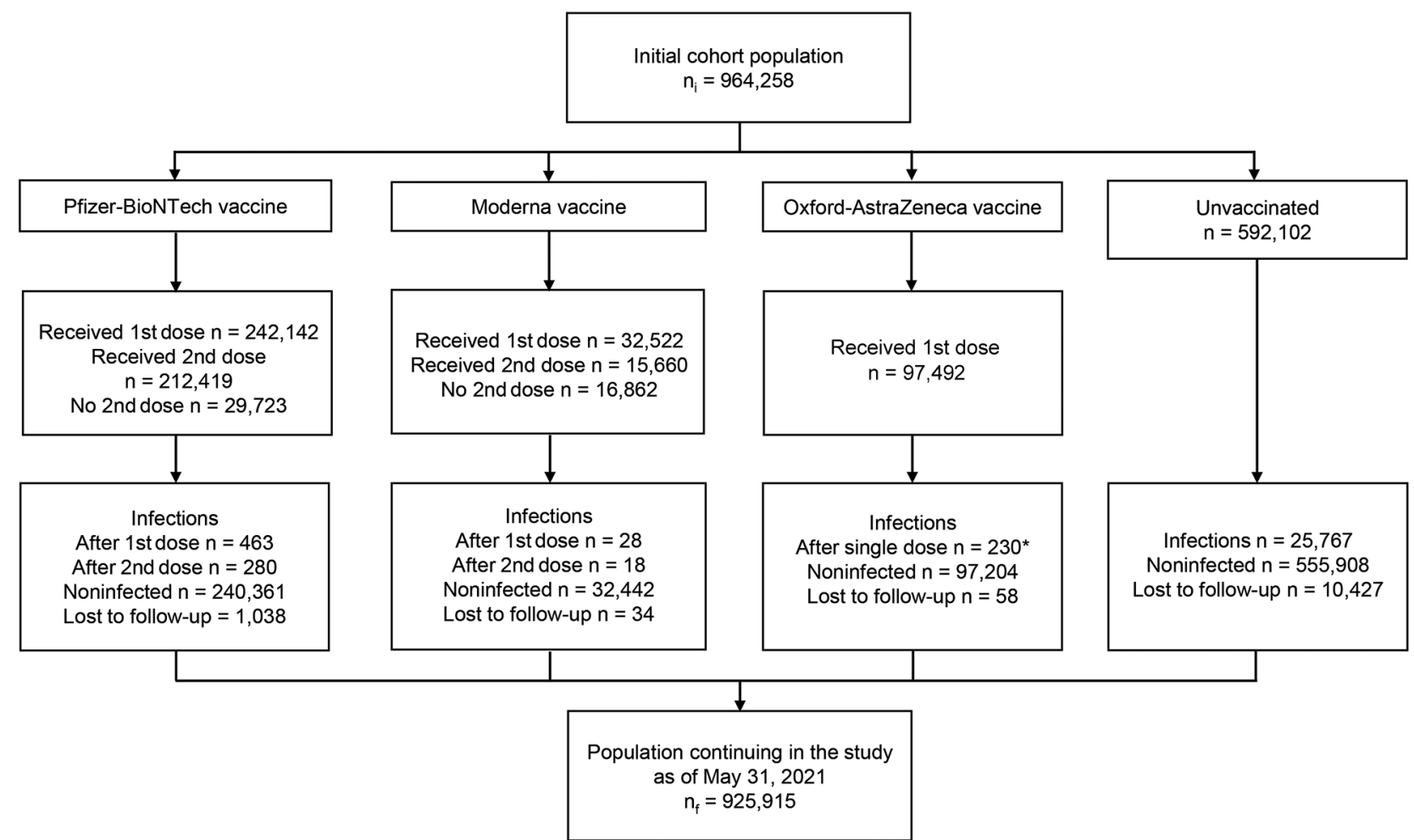

Figure 1. Flowchart of cohort evolution for study of coronavirus disease vaccines in preventing confirmed severe acute respiratory syndrome coronavirus 2 infection, Aragon, Spain, January-May 2021. *Participants vaccinated with the AZ vaccine had all received only 1 dose as of May 31, 2021.

Pfizer-BioNTech vaccine had $20.8 \%$ (95\% CI $11.6 \%-$ $29.0 \%$ ) adjusted VE after 1 dose and $70.0 \%$ (95\% CI $65.3 \%-74.1 \%$ ) after 2 doses. The Moderna vaccine had $52.8 \%$ (95\% CI 30.7\%-67.8\%) adjusted VE after 1 dose and $70.3 \%$ (95\% CI 52.2\%-81.5\%) after 2 doses; and the Oxford-AstraZeneca vaccine had $40.3 \%$ (95\% CI $31.8 \%-47.7 \%$ ) adjusted VE after 1 dose (Table 3$)$.

\section{SARS-CoV-2 Infection Cumulative Risk Curves}

For unvaccinated participants, the risk for SARSCoV-2 infection rose to $2 \%$ at day 44 and to $4 \%$ at day 154 of follow-up. For participants who received 1 dose of the Pfizer-BioNTech vaccine, the risk rose to $1 \%$ at day 40 of follow-up, but remained $<1 \%$ during the entire follow-up period (120 days) for those with 2 doses (Figure 2, panel A). For participants who received 1 dose of the Moderna vaccine, risk remained $<0.5 \%$ during the entire followup time (120 days) and for participants vaccinated with 2 doses, the risk rose from $0 \%$ to $0.5 \%$ during days $30-71$, then remained at $0.5 \%$ until the end of follow-up (day 90; Figure 2, panel B). For participants who received 1 dose of the Oxford-AstraZeneca vaccine, risk rose to $0.9 \%$ after 80 days of follow-up (Figure 2, panel C).

\section{Discussion}

In the general population, our findings showed an effectiveness of 3 different vaccines against SARSCoV-2 infection, but with lower efficacy estimates than from clinical trials and other VE studies. We found 20.8\% VE after 1 dose of the Pfizer-BioNTech vaccine and $70.0 \%$ after 2 doses; for the Moderna vaccine, these numbers were $52.8 \%$ VE after 1 dose and $70.3 \%$ VE after 2 doses, and for the Oxford-AstraZeneca vaccine, $40.3 \%$ after 1 dose.

For the Pfizer-BioNTech and Moderna vaccines, these values were lower than those in other observational studies, which had ranges of $61.9 \%-80 \% \mathrm{VE}$ after 1 dose and $90 \%-96 \%$ VE $\geq 7$ days after 2 doses $(8,9,27-29)$. These differences could possibly be explained by the population-wide design of our study, which included a higher percentage of elderly persons in the Pfizer-BioNTech-vaccinated group than in the other studies. In contrast, our results showed a higher VE after 2 doses of the Pfizer-BioNTech vaccine than the $65 \%$ VE found in another study (30), probably because they used a different approach for estimating VE that included only close contacts of positive cases and assigned every person in the cohort the same observation period and as a result vaccinated and 
Table 1. Characteristics of participants according to vaccination status at endpoint, Aragon, Spain, January-May 2021*

\begin{tabular}{|c|c|c|c|c|c|c|c|c|}
\hline Characteristic & $\begin{array}{c}\text { Initial cohort } \\
\text { population }\end{array}$ & $\begin{array}{l}\text { PBNT 1st } \\
\text { dose }\end{array}$ & $\begin{array}{l}\text { PBNT 2nd } \\
\text { dose }\end{array}$ & $\begin{array}{l}\text { MOD 1st } \\
\text { dose }\end{array}$ & $\begin{array}{l}\text { MOD 2nd } \\
\text { dose }\end{array}$ & $\begin{array}{c}\text { AZ single } \\
\text { dose }\end{array}$ & Unvaccinated & $\begin{array}{l}\text { Lost to } \\
\text { follow-up }\end{array}$ \\
\hline \multicolumn{9}{|l|}{ Age group, y } \\
\hline$<25$ & $92,287(9.6)$ & $1,745(0.7)$ & $1,489(0.7)$ & $338(1.0)$ & $155(1.0)$ & $3,440(3.5)$ & $\begin{array}{c}86,764 \\
(14.7)\end{array}$ & $\begin{array}{l}1,392 \\
(12.0)\end{array}$ \\
\hline $25-49$ & $\begin{array}{c}372,525 \\
(38.6)\end{array}$ & $\begin{array}{c}19,702 \\
(8.1)\end{array}$ & $\begin{array}{c}16,957 \\
(8.0)\end{array}$ & $\begin{array}{l}4,230 \\
(13.0)\end{array}$ & $\begin{array}{l}2,509 \\
(16.0)\end{array}$ & $\begin{array}{c}19,079 \\
(19.6)\end{array}$ & $\begin{array}{c}329,514 \\
(55.7)\end{array}$ & $\begin{array}{l}3,942 \\
(34.1)\end{array}$ \\
\hline $50-74$ & $\begin{array}{c}364,754 \\
(37.8)\end{array}$ & $\begin{array}{c}110,824 \\
(45.8)\end{array}$ & $\begin{array}{c}86,764 \\
(40.8)\end{array}$ & $\begin{array}{l}15,541 \\
(47.8)\end{array}$ & $\begin{array}{l}2,480 \\
(15.8)\end{array}$ & $\begin{array}{c}74,939 \\
(76.9)\end{array}$ & $\begin{array}{c}163,45 \\
(27.6)\end{array}$ & $\begin{array}{l}2,497 \\
(21.6)\end{array}$ \\
\hline$\geq 75$ & $\begin{array}{c}134,692 \\
(14.0) \\
\end{array}$ & $\begin{array}{c}109,871 \\
(45.4) \\
\end{array}$ & $\begin{array}{c}107,209 \\
(50.5) \\
\end{array}$ & $\begin{array}{c}12,413 \\
(38.2)\end{array}$ & $\begin{array}{l}10,516 \\
(67.2)\end{array}$ & $\begin{array}{c}34 \\
(0.0) \\
\end{array}$ & $\begin{array}{c}12,374 \\
(2.1) \\
\end{array}$ & $\begin{array}{l}3,726 \\
(32.2)\end{array}$ \\
\hline \multicolumn{9}{|l|}{ Sex } \\
\hline $\mathrm{F}$ & $\begin{array}{c}485,237 \\
(50.3)\end{array}$ & $\begin{array}{c}143,950 \\
(59.4)\end{array}$ & $\begin{array}{c}128,280 \\
(60.4)\end{array}$ & $\begin{array}{l}18,277 \\
(56.2)\end{array}$ & $\begin{array}{c}10,212 \\
(65.2)\end{array}$ & $\begin{array}{c}54,132 \\
(55.5)\end{array}$ & $\begin{array}{c}268,878 \\
(45.4)\end{array}$ & $\begin{array}{l}5,986 \\
(51.8)\end{array}$ \\
\hline M & $\begin{array}{c}479,021 \\
(49.7) \\
\end{array}$ & $\begin{array}{c}98,192 \\
(40.6) \\
\end{array}$ & $\begin{array}{c}84,139 \\
(39.6) \\
\end{array}$ & $\begin{array}{l}14,245 \\
(43.8) \\
\end{array}$ & $\begin{array}{l}5,448 \\
(34.8) \\
\end{array}$ & $\begin{array}{c}43,360 \\
(44.5) \\
\end{array}$ & $\begin{array}{c}323,224 \\
(54.6) \\
\end{array}$ & $\begin{array}{l}5,571 \\
(48.2) \\
\end{array}$ \\
\hline \multicolumn{9}{|l|}{ Site } \\
\hline Rural & $\begin{array}{c}354,418 \\
(36.8)\end{array}$ & $\begin{array}{c}93,723 \\
(38.7)\end{array}$ & $\begin{array}{c}82,281 \\
(38.7)\end{array}$ & $\begin{array}{l}5,154 \\
(15.8)\end{array}$ & $\begin{array}{l}1,373 \\
(8.8)\end{array}$ & $\begin{array}{c}35,387 \\
(36.3)\end{array}$ & $\begin{array}{c}220,154 \\
(37.2)\end{array}$ & $\begin{array}{l}4,741 \\
(41.0)\end{array}$ \\
\hline Urban & $\begin{array}{c}609,840 \\
(63.2) \\
\end{array}$ & $\begin{array}{c}148,419 \\
(61.3) \\
\end{array}$ & $\begin{array}{c}130,138 \\
(61.3) \\
\end{array}$ & $\begin{array}{c}27,368 \\
(84.2) \\
\end{array}$ & $\begin{array}{l}14,287 \\
(91.2)\end{array}$ & $\begin{array}{c}62,105 \\
(63.7) \\
\end{array}$ & $\begin{array}{c}371,948 \\
(62.8) \\
\end{array}$ & $\begin{array}{l}6,816 \\
(59.0)\end{array}$ \\
\hline \multicolumn{9}{|c|}{ Nursing and residential homes } \\
\hline Residents & $11,447(1.2)$ & $10,847(4.5)$ & $10,431(4.9)$ & $11(0.0)$ & $10(0.1)$ & $7(0.0)$ & $582(0.1)$ & $507(4.4)$ \\
\hline Workers & $10,174(1.1)$ & $8,734(3.6)$ & $8,570(4.0)$ & $46(0.1)$ & $6(0.0)$ & $155(0.2)$ & $1,239(0.2)$ & $33(0.3)$ \\
\hline $\begin{array}{l}\text { Follow-up, mean d } \\
\text { (SD) }\end{array}$ & $133(34.9)$ & $15.5(5.1)$ & $41(35.3)$ & $19.5(10.4)$ & $37.9(23.7)$ & $30.1(21.7)$ & $148.1(25.2)$ & $60.1(33.1)$ \\
\hline Total & $\begin{array}{c}964,258 \\
(100)\end{array}$ & $\begin{array}{c}242,142 \\
(100)\end{array}$ & $\begin{array}{c}212,419 \\
(100)\end{array}$ & $\begin{array}{c}32,522 \\
(100)\end{array}$ & $\begin{array}{c}15,660 \\
(100)\end{array}$ & $\begin{array}{c}97,492 \\
(100)\end{array}$ & $\begin{array}{c}592,102 \\
(100)\end{array}$ & $\begin{array}{c}11,557 \\
(100)\end{array}$ \\
\hline
\end{tabular}

unvaccinated participants most likely experienced similar exposure to SARS-CoV-2.

Our findings indicated a higher VE (52.8\%) after 1 dose of the Moderna vaccine than after 1 dose of either the Pfizer-BioNTech or Oxford-AstraZeneca vaccines and similar VEs after 2 doses of both the Moderna and Pfizer-BioNTech vaccines. However, our results did not reach the VE estimates of $83 \%$ after 1 dose and $82 \%$ after 2 doses of Moderna vaccine found in another study (28). The small sample size in that study, which only included healthcare personnel and other essential workers, might explain these differences in VE. However, as in that study (28), VE after 1 and 2 doses of the Moderna vaccine were also very close.

Safety concerns resulted in the suspension of the Oxford-AstraZeneca vaccine before anyone in our cohort received a second dose, and therefore we estimated VE only after 1 dose $(40.3 \%)$, similar to the $44 \%$ VE after 1 dose of the Oxford-AstraZeneca vaccine in another article (30). In contrast, another study found a VE of $60 \%$ against symptomatic disease after a single dose of the Oxford-AstraZeneca vaccine in adults $\geq 70$ years of age, as expected because of the study's more severe outcome measures and exclusively elderly population (14).

Cumulative risk curves of SARS-CoV-2 infection show that the cumulative risk of infection in unvaccinated participants rose to $4 \%$ at day 154 of follow-up whereas the risk remained $<1 \%$ during the entire follow-up period (120 days) in fully Pfizer-BioNTech-vaccinated participants, results consistent with those from a nationwide study (8). Risk remained $<0.5 \%$ in participants vaccinated with 1 dose of the Moderna vaccine during the entire follow-up time (120 days) and $<1 \%$ during the entire follow-up time (90 days) in fully vaccinated participants. In the participants with 2 doses of the Moderna vaccine, the slight increase in risk from day 30 onwards might be explained by the relatively small number of participants from our cohort who

Table 2. Causes of loss to follow-up during the study period, Aragon, Spain, January-May 2021

\begin{tabular}{lc}
\hline Causes & No. patients \\
\hline Expiration of service $^{*}$ & 3,328 \\
Death & 2,903 \\
Change of residence to another region of Spain & 2,020 \\
Loss of entitlement† & 250 \\
Change of residence to another country & 15 \\
Duplicate userf & 2 \\
Unknown & 3,039
\end{tabular}

${ }^{*}$ Aragon Health Service healthcare ended for administrative reasons. Most common were expiration of temporary service for persons who moved from another self-governing region of Spain for a specific period of time (maximum 6 months), subject to renewal; and for foreign citizens with no residence license who had not applied for renewal of Aragon Health Service-provided healthcare in 2 years.

†Loss of entitlement to Aragon Health Service-provided healthcare when person begins working unless they renounce mutual insurance companyprovided healthcare (applies to a few public workers in Spain whose healthcare provider is a mutual insurance company).

¥Health record of participant was duplicated in the Healthcare System Users Registry. 
Table 3. Effectiveness of Pfizer-BioNTech, Moderna, and Oxford-AstraZeneca coronavirus disease vaccines in preventing confirmed SARS-CoV-2 infection, Aragon, Spain, January-May 2021*

\begin{tabular}{|c|c|c|c|c|c|c|c|c|}
\hline Vaccination status & $\begin{array}{l}\text { Person-days, } \\
\text { total (average) }\end{array}$ & Population & $\begin{array}{c}\text { SARS-CoV-2 } \\
\text { infections }\end{array}$ & $\mathrm{IR} \dagger$ & $\begin{array}{l}\text { Unadj } \\
\text { HR } \ddagger\end{array}$ & $\begin{array}{l}\text { Adj } \\
\text { HR } \ddagger\end{array}$ & $\begin{array}{c}\text { Unadj VE,§ \% } \\
(95 \% \mathrm{Cl})\end{array}$ & $\begin{array}{c}\text { Adj VE, § \% } \\
(95 \% \mathrm{Cl})\end{array}$ \\
\hline \multicolumn{9}{|l|}{ Pfizer-BioNTech } \\
\hline 1 dose & $3,750,582(15.5)$ & 242,142 & 463 & 0.86 & 0.77 & 0.79 & $23.5(16.0-30.3)$ & $20.8(11.6-29.0)$ \\
\hline 2 doses & $0(41.0)$ & 19 & 280 & 0.23 & 0.24 & 0.30 & $3.1-78.8)$ & $70.0(65.3-74.1)$ \\
\hline \multicolumn{9}{|l|}{ Moderna } \\
\hline 1 dose & $1(19.5)$ & 32,522 & 28 & 0.31 & 0.31 & 0.47 & $69.2(55.4-78.8)$ & $52.8(30.7-67.8)$ \\
\hline 2 doses & 592,877 (37.9) & 15,660 & 18 & 0.21 & 0.22 & 0.30 & $78.4(65.6-86.4)$ & $70.3(52.2-81.5)$ \\
\hline \multicolumn{9}{|l|}{ Oxford-AstraZeneca } \\
\hline 1 dose & $(30.1)$ & & 230 & 0.55 & 0.56 & 0.60 & $43.7(35.7-50.7)$ & $40.3(31.8-47.7)$ \\
\hline Unvaccinated & $128,261,888(133.0)$ & 592,102 & 25,767 & 1.41 & 1.00 & 1.00 & NA & NA \\
\hline
\end{tabular}

*Adj, adjusted; HR, hazard ratio; IR, incidence rate; NA, not applicable; SARS-CoV-2, severe acute respiratory syndrome coronavirus; unadj, unadjusted; VE, vaccine effectiveness.

†Incidence rate of SARS-CoV-2 infection was measured in 1,000 person-weeks (not person-days) to make it to read the table (estimates expressed with $\leq 2$ decimals).

¥HR was adjusted by age, sex, work, or residence in nursing or residential homes, weekly cumulative incidence in each primary care service area, and number of SARS-CoV-2 tests administered in the previous 6 months.

$\S$ Vaccine effectiveness against SARS-CoV-2 infection was calculated as $1-\mathrm{HR}$.

were vaccinated with the second dose and reached long follow-up times ( $\geq 50$ days), which can cause instability of estimates for prolonged follow-up times. For the Oxford-AstraZeneca vaccine, the difference in risk between unvaccinated participants and those vaccinated with 1 dose ( $2.5 \%$ vs. $0.9 \%$ at day 80 of follow-up) highlights the VE after 1 dose of the Oxford-AstraZeneca vaccine.

One limitation of our study was losses to followup because of administrative leaves from AHSUR. Participants lost to follow-up were statistically different from the studied cohort. Nevertheless, they represent only $1.2 \%$ of the initial population, which limited the magnitude of this bias. Timing of vaccine rollout also varied between priority groups, targeted for earlier vaccination, and the general population. This difference may have affected the results by adding more variability, particularly because Pfizer-BioNTech was mostly used in population $\geq 75$ years of age, who were vaccinated earlier, whereas Oxford-AstraZeneca was mostly used in general population, who were vaccinated at a later time.

Research has documented that the proportion of symptomatic infections in vaccinated persons is lower than in unvaccinated ones because vaccination prevents symptoms (28). Therefore, studies based on symptomatic persons $(1-7,11,13,14)$ underestimate the total infection rate in vaccinated persons to a greater extent than in unvaccinated ones and consequently overestimate VE. Our study included all confirmed symptomatic and asymptomatic SARS-CoV-2 infections, and thus it would be expected that VE
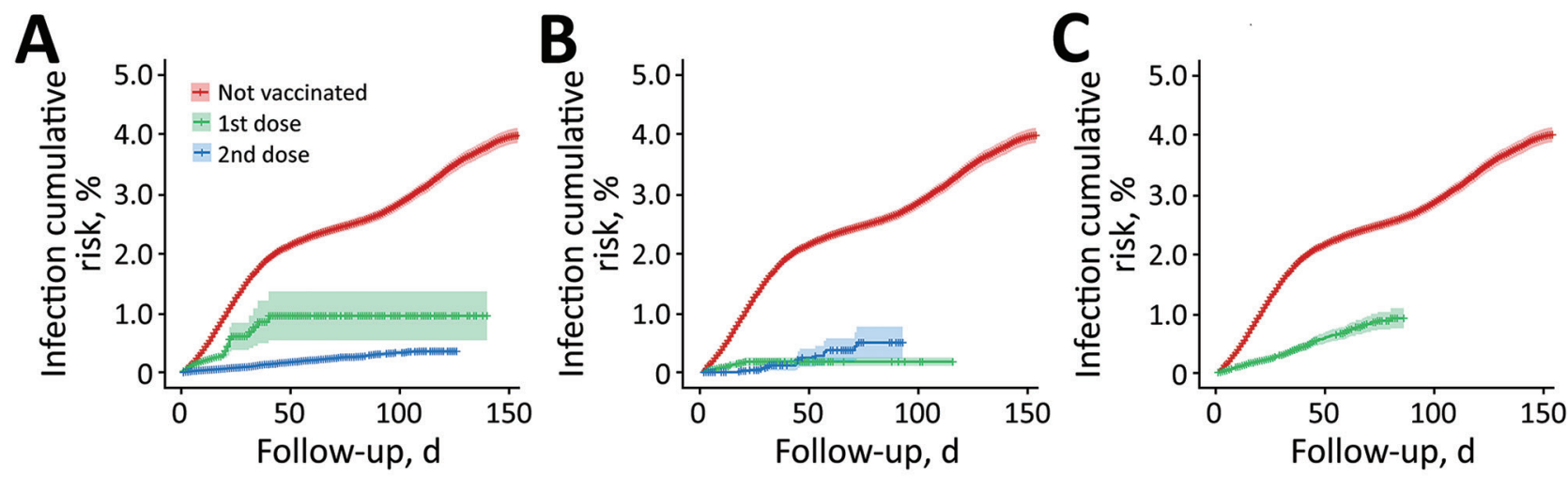

Figure 2. Cumulative risk curves (1 minus the Kaplan-Meier risk) of severe acute respiratory syndrome coronavirus 2 (SARSCoV-2) infection for 3 coronavirus disease vaccines, Aragon, Spain, January-May 2021. A) BioNTech-Pfizer BNT162b2 mRNA, B) Moderna mRNA-1273, and C) Oxford-AstraZeneca ChAdOx1-S-AZD1222. Shadows across lines represent $95 \%$ CI. For unvaccinated participants, $95 \% \mathrm{Cl}$ at day 90 of follow-up was $2.6 \%-2.8 \%$. For participants who went on to receive the BioNTech-Pfizer vaccine, $95 \%$ $\mathrm{Cl}$ at day 90 of follow-up was $0.5 \%-1.4 \%$ (1 dose) and $0.3 \%-0.4 \%$ ( 2 doses). For the Moderna vaccine, $95 \% \mathrm{Cl}$ at day 90 of follow-up was $0.1 \%-0.2 \%$ ( 1 dose), and $0.2 \%-0.8 \%$ (2 doses). For Oxford-AstraZeneca, $95 \% \mathrm{Cl}$ at day 90 of follow-up was $0.7 \%-1.0 \%(1$ dose). Cumulative risk curves of SARS-CoV-2 infection start from the day after vaccination when full protection against SARS-CoV-2 infection is thought to begin, according to previous studies (1-3). The hairs on both sides of the lines represent participants lost to follow-up; gaps represent periods of time between losses. 
would be lower than in studies only including symptomatic disease and our VE estimates more relevant to transmission control, because in real-world conditions, symptomatic and asymptomatic infections coexist and both contribute to transmission.

Similarly, according to COVID-19 detection and surveillance guidelines in Spain and Aragon $(25,26)$, tests were administered less frequently to asymptomatic than to symptomatic persons, resulting in underdetection of asymptomatic infections. This bias was reduced because underdetection occurred in both vaccinated and unvaccinated persons but could still lead to overestimating VE. On the other hand, also following the detection program guidelines, tests were administered to close contacts regardless of their vaccination status, which reduced the chance of detection bias in our study. However, routine screenings carried out in nursing and residential homes could have altered our findings if there were more screenings in vaccinated than in unvaccinated participants. The role of dominant variants of concern in the transmission was unknown at the time of our data analyses. The rapid circulation of these variants may have introduced confounding, but it was minimized by including weekly variability, and therefore calculated VE estimates represent a summarized measure against all variants, adjusted by incidence. Practical factors such as hygiene and social distance measures might also have affected the estimates of VE.

Our study shows great strength in statistical power because of the large population cohort and use of a refined methodology. Risk of infection differed between participants according not only to vaccination status but also to the evolution of the epidemic curve. For this reason, we used an approach of weekly repeated measures, adjusted by WCI in each primary care service area.

In conclusion, we found effectiveness against SARS-CoV-2 infection for Pfizer-BioNTech, Moderna, and Oxford-AstraZeneca vaccines to be lower than efficacy estimates from clinical trials and other VE studies. Even if high vaccination coverages are reached in the general population $(31,32)$, effectively minimizing transmission opportunities might be limited, because age groups of persons $<12$ years of age were not being immunized at the time of our data gathering. Even so, reaching high vaccination coverage is important to decrease SARS-CoV-2 transmission in the general population.

\section{Acknowledgments}

The authors thank the anonymous reviewers and editors for their helpful suggestions.

\section{About the Author}

Ms. del Cura is currently working as a preventive medicine and public health specialist in the Populationbased Screening Coordination Unit at the Aragon Department of Health, Zaragoza, Spain. Her primary research interests include public health issues such as vaccination effectiveness, epidemiology of communicable and noncommunicable diseases, and health promotion.

\section{References}

1. Baden LR, El Sahly HM, Essink B, Kotloff K, Frey S, Novak R, et al.; COVE Study Group. Efficacy and safety of the mRNA-1273 SARS-CoV-2 vaccine. N Engl J Med. 2021;384:403-16. https://doi.org/10.1056/NEJMoa2035389

2. Polack FP, Thomas SJ, Kitchin N, Absalon J, Gurtman A, Lockhart S, et al.; C4591001 Clinical Trial Group. Safety and efficacy of the BNT162b2 mRNA Covid-19 vaccine. N Engl J Med. 2020;383:2603-15. https:/ / doi.org/10.1056/ NEJMoa2034577

3. Voysey M, Costa Clemens SA, Madhi SA, Weckx LY, Folegatti PM, Aley PK, et al.; Oxford COVID Vaccine Trial Group. Single-dose administration and the influence of the timing of the booster dose on immunogenicity and efficacy of ChAdOx1 nCoV-19 (AZD1222) vaccine: a pooled analysis of four randomised trials. [Erratum in: Lancet. 2021;397:880]. Lancet. 2021;397:881-91. https://doi.org/10.1016/ S0140-6736(21)00432-3

4. Sadoff J, Gray G, Vandebosch A, Cárdenas V, Shukarev G, Grinsztejn B, et al.; ENSEMBLE Study Group. Safety and efficacy of single-dose Ad26.COV2.S vaccine against Covid-19. N Engl J Med. 2021;384:2187-201. https:/ / doi.org/ 10.1056/NEJMoa2101544

5. Logunov DY, Dolzhikova IV, Shcheblyakov DV, Tukhvatulin AI, Zubkova OV, Dzharullaeva AS, et al.; Gam-COVID-Vac Vaccine Trial Group. Safety and efficacy of an rAd26 and rAd5 vector-based heterologous prime-boost COVID-19 vaccine: an interim analysis of a randomised controlled phase 3 trial in Russia. Lancet. 2021;397:671-81. https:/ / doi.org/10.1016/S0140-6736(21)00234-8

6. Al Kaabi N, Zhang Y, Xia S, Yang Y, Al Qahtani MM, Abdulrazzaq N, et al. Effect of 2 inactivated SARS-CoV-2 vaccines on symptomatic COVID-19 infection in adults: a randomized clinical trial. JAMA. 2021;326:35-45. https://doi.org/10.1001/jama.2021.8565

7. Shinde V, Bhikha S, Hoosain Z, Archary M, Bhorat Q, Fairlie L, et al.; 2019nCoV-501 Study Group. 2019nCoV-501 Study Group. 2019nCoV-501 Study Group. Efficacy of NVX-CoV2373 Covid-19 vaccine against the B.1.351 variant. N Engl J Med. 2021;384:1899-909. https://doi.org/10.1056/ NEJMoa2103055

8. Dagan N, Barda N, Kepten E, Miron O, Perchik S, Katz MA, et al. BNT162b2 mRNA Covid-19 vaccine in a nationwide mass vaccination setting. N Engl J Med. 2021;384:1412-23. https://doi.org/10.1056/NEJMoa2101765

9. Haas EJ, Angulo FJ, McLaughlin JM, Anis E, Singer SR, Khan F, et al. Impact and effectiveness of mRNA BNT162b2 vaccine against SARS-CoV-2 infections and COVID-19 cases, hospitalisations, and deaths following a nationwide vaccination campaign in Israel: an observational study using national surveillance data. Lancet. 2021;397:1819-29. https:/ / doi.org/10.1016/S0140-6736(21)00947-8

10. McDonald I, Murray SM, Reynolds CJ, Altmann DM, Boyton RJ. Comparative systematic review and meta-analysis 
of reactogenicity, immunogenicity and efficacy of vaccines against SARS-CoV-2. NPJ Vaccines. 2021;6:74. https:/ / doi.org/10.1038/ s41541-021-00336-1

11. Vasileiou E, Simpson CR, Shi T, Kerr S, Agrawal U, Akbari A, et al. Interim findings from first-dose mass COVID-19 vaccination roll-out and COVID-19 hospital admissions in Scotland: a national prospective cohort study. Lancet. 2021;397:1646-57. https://doi.org/10.1016/ S0140-6736(21)00677-2

12. Hall VJ, Foulkes S, Saei A, Andrews N, Oguti B, Charlett A, et al.; SIREN Study Group. COVID-19 vaccine coverage in health-care workers in England and effectiveness of BNT162b2 mRNA vaccine against infection (SIREN): a prospective, multicentre, cohort study. Lancet. 2021; 397:1725-35. https://doi.org/10.1016/S0140-6736 (21)00790-X

13. Hyams C, Marlow R, Maseko Z, King J, Ward L, Fox K, et al. Effectiveness of BNT162b2 and ChAdOx1 nCoV-19 COVID-19 vaccination at preventing hospitalisations in people aged at least 80 years: a test-negative, case-control study. [Erratum in Lancet Infect Dis. 2021;21:e208]. Lancet Infect Dis. 2021;21:1539-48. https://doi.org/10.1016/ S1473-3099(21)00330-3

14. Lopez Bernal J, Andrews N, Gower C, Robertson C, Stowe J, Tessier E, et al. Effectiveness of the Pfizer-BioNTech and Oxford-AstraZeneca vaccines on covid-19 related symptoms, hospital admissions, and mortality in older adults in England: test negative case-control study. BMJ. 2021;373:n1088. https://doi.org/10.1136/bmj.n1088

15. Johns Hopkins University. Coronavirus resource center. [cited 2021 Aug 1] https:/ / coronavirus.jhu.edu/ map.html

16. Government of Aragon (Spain). Aragon population register. Population pyramids [in Spanish]. [cited 2021 Aug 1] https:/ / www.aragon.es/-/ piramides-de-poblacion.-aragon

17. Aragon Department of Health. Aragonese COVID-19 epidemiological report [in Spanish], Zaragoza, Spain [cited 2021 Jul 31] https:/ / datacovid.salud.aragon.es/covid

18. García-Montero C, Fraile-Martínez O, Bravo C, Torres-Carranza D, Sanchez-Trujillo L, Gómez-Lahoz AM, et al. An updated review of SARS-CoV-2 vaccines and the importance of effective vaccination programs in pandemic times. Vaccines (Basel). 2021;9:433. https://doi.org/10.3390/ vaccines 9050433

19. European Medicines Agency. COVID-19 vaccines authorized: vaccines authorised in the European Union (EU) to prevent COVID-19, following evaluation by the European Medicines Agency (EMA) [cited 2021 Jun 9]. https:/ / www. ema.europa.eu/en/human-regulatory/overview/publichealth-threats/coronavirus-disease-covid-19/treatmentsvaccines/vaccines-covid-19/covid-19-vaccines-authorised

20. Interterritorial Board of the Spanish National Health System. COVID-19 vaccination strategy in Spain, 8th update [in Spanish]. 2021 Jun 22 [cited 2021 Aug 1]. https:/ / www. mscbs.gob.es/profesionales/saludPublica/prevPromocion/ vacunaciones/covid19/docs/COVID-19_Actualizacion8_ EstrategiaVacunacion.pdf

21. Aragon Department of Health. Action plan for COVID-19 vaccination in Aragon, updated 2021 May 3 [in Spanish] [cited 2021 Aug 1]. https:/ / www.aragon.es/documents/ 20127/1650151/Plan_Operativo_Vacunacion_Covid19_ Aragon_20210503.pdf
22. Aragon Department of Health. Aragon weekly epidemiologic bulletin, week 20 (2021 May 17-23) [in Spanish] [cited 2021 Aug 1] https:/ / www.aragon.es/ documents/20127/1650151/BEsA_202021.pdf

23. Aragon Department of Health. Aragon weekly epidemiologic bulletin, week 29 (2021 July 19-25) [in Spanish] [cited 2021 Aug 1] https:/ / www.aragon.es/documents/20127/ 1650151/BEsA_292021.pdf

24. World Health Organization. Public health surveillance for COVID-19: interim guidance. 2020 Dec 16 [cited 2021 Aug 1]. https://www.who.int/publications/i/item/ who-2019-nCoV-surveillanceguidance-2020.8

25. Spanish Directorate-General of Public Health, Spanish Department of Health. Strategy for early detection, surveillance and control of COVID-19, updated 2021 Jul 23 [in Spanish] [cited 2021 Aug 1] https://www.mscbs.gob.es/ profesionales/saludPublica/ccayes/alertasActual/nCov/ documentos/COVID19_Estrategia_vigilancia_y_control_e_ indicadores.pdf

26. Aragon Department of Health. General procedure for COVID-19 healthcare in Aragon, updated 2021 Jun 29 [in Spanish] [cited 2021 Aug 1]. https:/ / www.aragon.es/ documents/20127/1650151/20210629_Procedimiento_ COVID_19_Aragon.pdf

27. Bianchi FP, Germinario CA, Migliore G, Vimercati L, Martinelli A, Lobifaro A, et al.; Control Room Working Group. BNT162b2 mRNA Covid-19 vaccine effectiveness in the prevention of SARS-CoV-2 infection: a preliminary report. J Infect Dis. 2021;224:431-4. https:/ / doi.org/10.1093/ infdis/jiab262

28. Thompson MG, Burgess JL, Naleway AL, Tyner HL, Yoon SK, Meece J, et al. Interim estimates of vaccine effectiveness of BNT162b2 and mRNA-1273 COVID-19 vaccines in preventing SARS-CoV-2 infection among health care personnel, first responders, and other essential and frontline workers - eight U.S. locations, December 2020March 2021. MMWR Morb Mortal Wkly Rep. 2021;70:495500. https:/ / doi.org/10.15585/mmwr.mm7013e3

29. Chodick G, Tene L, Rotem RS, Patalon T, Gazit S, Ben-Tov A, et al. The effectiveness of the two-dose BNT162b2 vaccine: analysis of real-world data. Clin Infect Dis. 2021 May 17 [Epub ahead of print]. https:/ / doi.org/10.1093/cid/ciab438

30. Martínez-Baz I, Miqueleiz A, Casado I, Navascués A, Trobajo-Sanmartín C, Burgui C, et al.; Working Group for the Study of COVID-19 in Navarra. Effectiveness of COVID-19 vaccines in preventing SARS-CoV-2 infection and hospitalisation, Navarre, Spain, January to April 2021. Euro Surveill. 2021;26:2100438. https:// doi.org/10.2807/ 1560-7917.ES.2021.26.21.2100438

31. Frederiksen LSF, Zhang Y, Foged C, Thakur A. The long road toward COVID-19 herd immunity: vaccine platform technologies and mass immunization strategies. Front Immunol. 2020;11:1817. https:/ / doi.org/10.3389/ fimmu.2020.01817

32. Randolph HE, Barreiro LB. Herd Immunity: Understanding COVID-19. Immunity. 2020;52:737-41. https://doi.org/ 10.1016/j.immuni.2020.04.012

Address for correspondence: Alicia del Cura-Bilbao, Aragon Department of Health, 36 Vía Univérsitas, 50017 Zaragoza, Spain; email: adelcura@salud.aragon.es 